Oncología en Imágenes

\title{
Tumoración craneal y paraparesia de extremidades inferiores
}

\author{
A. Hermida-Ameijeiras ${ }^{1}$, A. Van den Eynde ${ }^{1}$, R. M. Reyes Santías ${ }^{2}$
}

\section{Resumen}

Introducción: Habitualmente el carcinoma microcítico de pulmón (oat-cell) debuta con sintomatología respiratoria y/o hallazgos radiológicos pulmonares.

Caso clínico: El caso clínico presentado muestra un paciente con una masa craneal metastásica y síndrome de compresión medular como debut de un oat-cell pulmonar.

Conclusiones: Es necesario un alto índice de sospecha clínica para detectar precozmente los carcinomas microcíticos de pulmón en estadío limitado. Sin embargo, casos como el aportado reflejan el comportamiento agresivo del mismo con un elevado porcentaje de estadíos diseminados al diagnóstico y elevada morbimortalidad.

Palabras clave: Carcinoma microcítico pulmonar. Metástasis craneales. Compresión medular. Ttf-1.

Oncología, 2007; 30 (1):32-36

\section{Summary}

Introduction: Small cell lung cancer (oat.cell carcinoma) comes up usually with respiratory symptoms and/or radiological findings.

Clinical case: This clinical case corresponds to a patient with a metastatic skull mass and medullary compression syndrome as a debut of an oat cell lung cancer.

Conclusions: A very marked suspicion is necessary for the clinical early diagnosis of small cell lung cancer with limited disease. Nevertheless, cases as the one reported here manifest its aggressiveness, with a high rate of dissemination at diagnosis and a high morbimortality.

Key words: Small cell lung cancer. Skull metastases. Medullary compression. Ttf-1.

1 Servicio de Medicina Interna.

2 Servicio de Anatomía Patológica.

Hospital Clínico Universitario de Santiago de Compostela.

Santiago de Compostela (A Coruña). España. 


\section{Caso clínico}

Aportamos el caso de un varón de 51 años, sin antecedentes de interés, fumador de 60 paquetes/ año, que acude por lumbalgia de dos meses de evolución con adelgazamiento de $12 \mathrm{~kg}$ y debilidad progresiva en extremidades inferiores. Además, advierte tumoración indolora fronto-orbitaria derecha de crecimiento progresivo. La exploración física evidencia paraparesia con hiperreflexia de extremidades inferiores y globo vesical, así como la tumoración descrita de consistencia gomosa, de $4 \times 4 \mathrm{~cm}$ con exoftalmos derecho asociado.
En los estudios analíticos destaca únicamente elevación de VSG (19 mms) y fibrinógeno $(576 \mathrm{mg} / \mathrm{dl})$, CEA-II $(418,6 \mathrm{ng} / \mathrm{mL})$, TPS $(116$ U/L) y Enolasa N.E. $(98,8 \mathrm{ng} / \mathrm{mL})$. La radiología simple de tórax no evidencia alteraciones mientras que las pruebas de neuroimagen muestran lesión craneal expansiva (Figura 1) y lesión osteolítica en D12 con compresión medular asociada (Figura 2). También se objetivaron lesiones hepáticas metastásicas. La biopsia de la lesión ósea muestra infiltración por células pequeñas y redondas y expresión de citoqueratinas y marcadores neuroendocrinos así como del factor de transcripción tiroideo

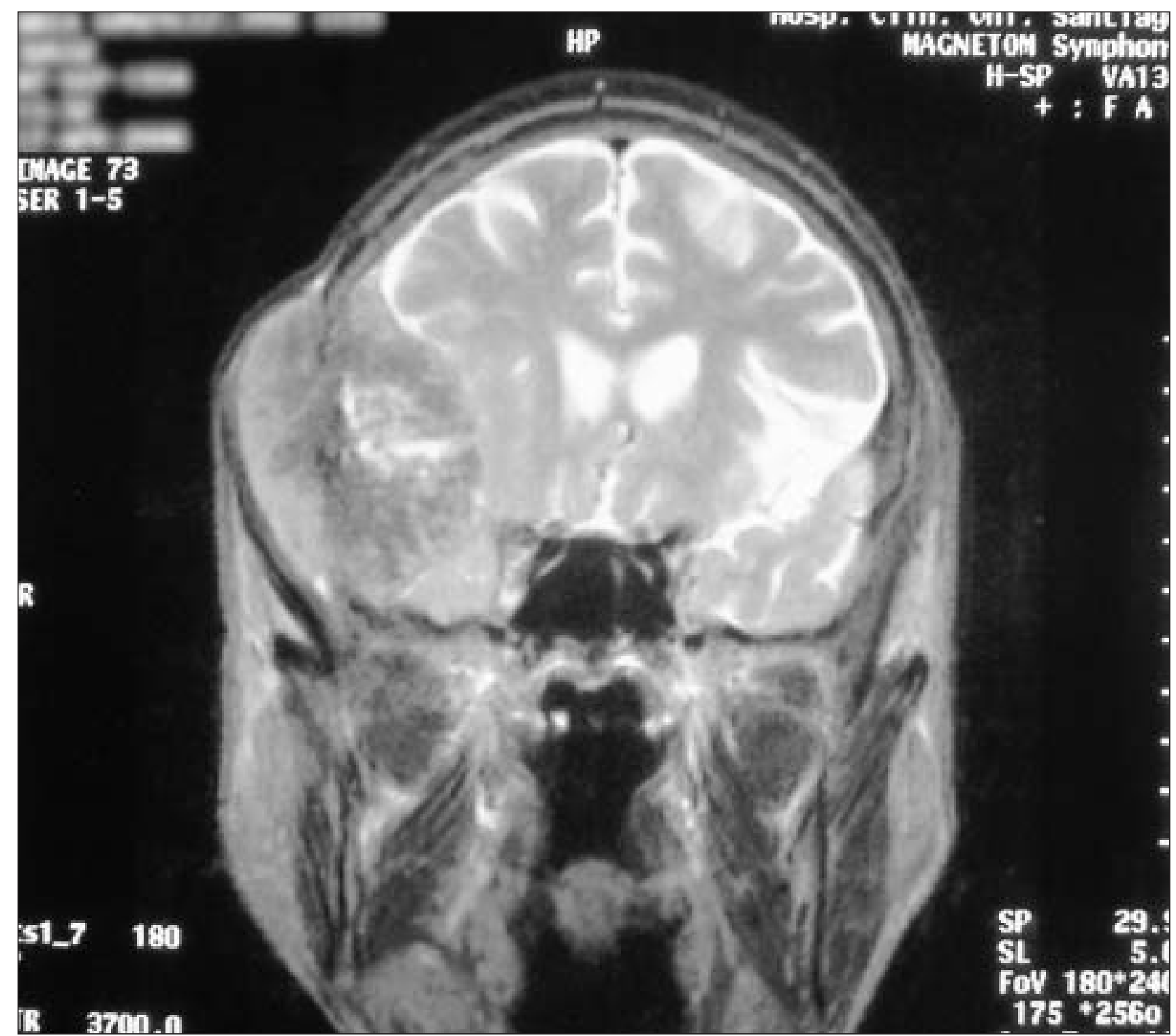

Figura 1. Imagen en resonancia nuclear magnética (RNM) de la tumoración lítica con expansión hacia tejidos blandos subcutáneos e intracraneal. 


\section{A. Hermida-Ameijeiras y cols.}

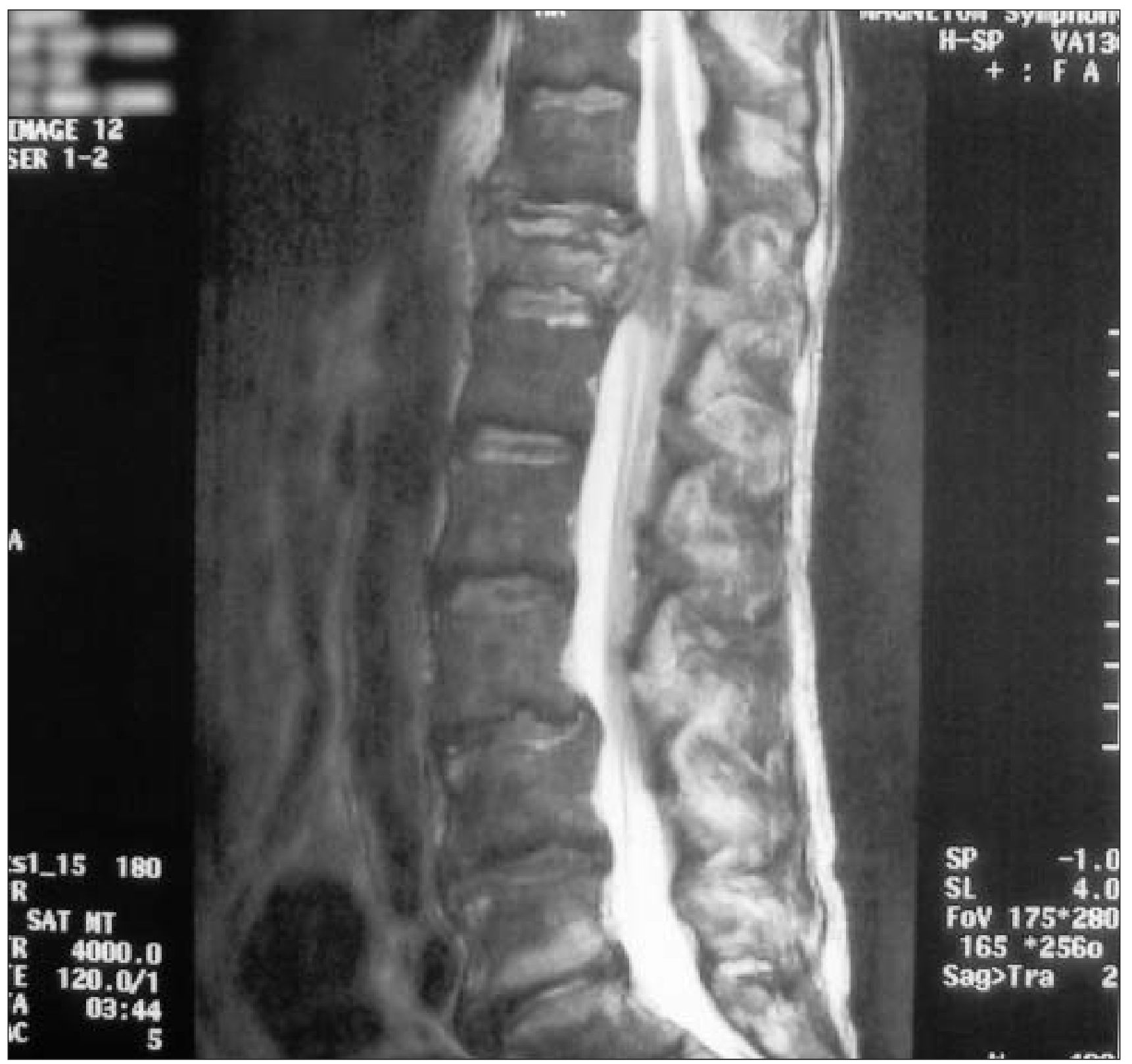

Figura 2. RNM de columna dorsolumbar mostrando lesión lítica a nivel de D12, que se extiende a espacio epidural anterior produciendo compresión medular.

(TTf-1) (Figura 3), estableciéndose el diagnóstico de carcinoma metastático tipo oat-cell de origen primario pulmonar.

El paciente recibió radioterapia vertebral y exére- sis de lesión craneal, que invadía duramadre, con reconstrucción ósea. Dado su estado general se decidió manejo sintomático ambulatorio, falleciendo cinco meses después. 


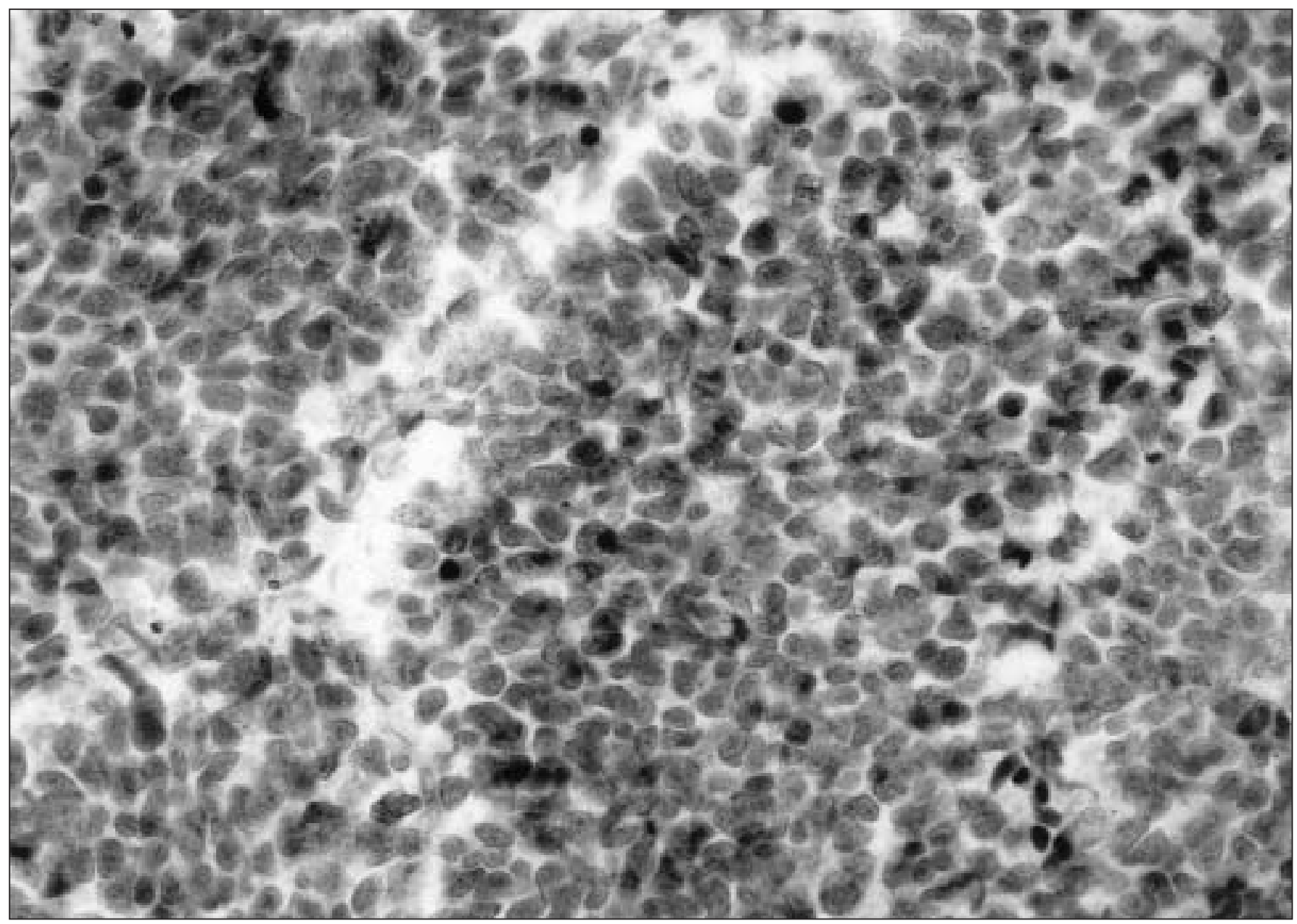

Figura 3. Imagen microscópica (400X) con tinción inmunohistoquímica para Factor de Transcripción Tiroideo (TTf-1), procedente de la biopsia de la lesion fronto-orbitaria.

\section{Discusión}

El cáncer de pulmón fue responsable del 8,16\% de las muertes en varones en el año 2000 en España ${ }^{1}$ siendo el carcinoma microcítico el de peor pronóstico, con más del 55\% de estadíos avanzados al diagnóstico ${ }^{2}$ y supervivencia media de nueve meses ${ }^{3}$.

$\mathrm{El}$ factor de riesgo más importante es el hábito tabáquico, presente en más del $90 \%$ de los casos ${ }^{4}$. Debuta con sintomatología respiratoria hasta en un $72,2 \%{ }^{4}$ y los estudios radiológicos muestran lesión expansiva hasta en un 96,2\% $\%^{5}$. El síndrome de compresión medular aparece en el 2,5\% de pacientes ${ }^{3}$.

Más de un $70 \%$ de los pacientes tienen enfermedad diseminada al diagnóstico y su supervivencia al año gira en torno al $16 \%$ en contraposición al $75 \%$ en pacientes con enfermedad limitada ${ }^{3}$. Un alto índice de sospecha sigue siendo necesario en la práctica habitual para mejorar esta variable ${ }^{5}$.
Este caso ilustra el inusual debut de un carcinoma microcítico de pulmón con metástasis óseas y sintomatología puramente neurológica sin hallazgos clínicos ni radiológicos que orienten la naturaleza del tumor primitivo. Resultó determinante la positividad para citoqueratinas, la cromogranina A o la sinaptofisina y el factor de transcripción tiroideo (TTf-1) que nos sirvió para establecer el origen pulmonar del mismo.

Correspondencia:

Dr. A. Hermida Ameijeiras

Servicio de Medicina Interna

Hospital Clinico Univ. de Santiago de Compostela Avda. Choupana, s/n

E-15706 Santiago de Compostela (A Coruña) alvarohermida@tiscali.es 


\section{A. Hermida-Ameijeiras y cols.}

\section{Bibliografía}

1. Instituto Nacional de Estadística. Fallecimiento en España por todas las causas (año 2003). Available from: www.ine.es.

2. Santos-Martínez MJ, Curull V, Blanco ML, Macía F, Mojal S, Villa J, Broquetas JM. Lung Cancer at a University Hospital: Epidemiological and Histological Characteristics of a Recent and a Historical Series. Arch Bronconeumol. 2005; 41 (6): 307-12.

3. Samanez-Figari CA, Carracedo-Gonzalez C, Amorín-Kahatt E, Vallejos-Sologuren C. Cáncer de pulmón a células pequeñas: experiencia de 10 años en el Instituto de enfermeda- des neoplásicas "Eduardo Cáceres Graziani”. Acta Cancerol 2002; 31 (1).

4. Carcereny-Costa E, Maximiano C, López-García Gallo C, Cajón E, de la Fuente-Alonso C, Espina R, Provencio M, España P. Carcinoma microcítico de pulmón: análisis clínico. Arch Bronconeumol 2004; 40: 71-90.

5. Sánchez de Cos-Escuín J, Disdier-Vicente C, Corral-Peñafiel J, Riesco-Miranda JA, Sojo-González MA, Masa Jiménez JF. Overall long-term survival in Lung Cancer analyzed in 610 unselected patients. Arch Bronchoneumol 2004; 40 (6): $268-74$ 